\title{
VENEREAL DISEASES OF ANIMALS
}

By REGINALD LOVELL, Research Institute in Animal Pathology, Royal Veterinary College, London

THE "Shorter Oxford English Dictionary" defines "venereal" as :-

(I) of or pertaining to, associated or connected with sexual desire or intercourse ;

(2) resulting from or communicated by sexual intercourse with an infected person; symptomatic of or associated with a disease (I658).

I am therefore selecting several animal diseases in which natural transmission is either wholly or largely by the act of coitus. It would obviously be impossible to include those contagious diseases in which infection may occasionally be transmitted in this manner.

Examples selected include :-

(I) Brucella infection of animals, particularly of pigs.

(2) Spirochætosis, with special reference to that of rabbits, often called rabbit syphilis.

(3) A trypanosomiasis of horses, namely dourine.

(4) A trichomonas infection of cattle.

(5) Tumour formation on the genitalia of dogs.

(6) A composite condition affecting the vagina of cows and, less commonly, horses and sheep.

\section{(I) BRuCELla InFEction}

There are three main types of Brucella, all of which may infect man.

(I) Brucella melitensis, isolated by Bruce in 1887 , the cause of undulant fever in man, and also a cause of disease in goats and sheep.

(2) Brucella abortus, isolated by Bang and Stribolt in I896, producing abortion in cattle and isolated less frequently from other domesticated animals.

(3) Brucella abortus suis, or Br. suis, isolated by Traum in I9I4 from aborted porcine foetuses.

Brucella abortus. - Brucella abortus infections are very I92 


\section{VENEREAL DISEASES OF ANIMALS}

common in Great Britain. Natural infection may take place in cows by way of :-

(i.) the mouth. Many observers consider this the most common method, for uterine exudate may contaminate foodstuffs and at the time of abortion be rich in brucella organisms which may remain alive for a long time. Moreover, the milk of infected cows may contain $\mathrm{Br}$. abortus.

(ii.) the vagina. Although the vagina may be infected by contaminated litter, the bull may sometimes be responsible, and it is known that bulls may secrete $B r$. abortus in their seminal fluid after experimental infection. (Seddon, I9I9.)

(iii.) skin and conjunctiva. Bovines may be infected experimentally by this route.

In contagious abortion of cattle, the relative importance of these points of entry is not known, and most observers think that sexual intercourse plays a minor part, and that infection through the mouth is more usual. This applies to goats and sheep also, though with these animals infection through the skin and mucosa is possibly more common than among cattle.

Brucella suis.-Thomsen (I934), in a recent study of an outbreak of infection among pigs in Denmark, indicates that this condition is spread largely by the boar during the act of coition, and an account of Thomsen's studies will therefore be given later.

Infection of pigs with $\mathrm{Br}$. suis is well known in America and in Denmark, but apparently does not occur in this country (Doyle, I934). It is essentially a disease of the reticulo-endothelial system, with evidence of disturbance in the glands, joints and reproductive system. The essential difference between infection of swine and infection of cattle is that in swine it is mainly a disease of males and transmitted by the male to females, whereas the bovine infection is largely one of females, and produces abortion.

In infected herds of swine, the sera of breeding boars often contain antibodies for Brucella, and their presence may be demonstrated by the agglutination and complement fixation tests. The reacting boars often show purulent or necrotic processes, sometimes with calcification, in the genitals and especially in the epididymis, 


\section{BRITISH JOURNAL OF VENEREAL DISEASES}

and perhaps in the testicles and seminal vesicles. These organs may become atrophied and impotence may result. Brucella suis may be demonstrated in the various genital glands.

In the sow, infection may be manifested by what Thomsen has described as "miliary brucellosis of the uterus." Numerous well-defined whitish-yellow nodules appear in the deeper layer of the mucous membrane. Pregnant sows may abort, but this sequel is relatively less common than in the bovine infection.

Although Brucella suis may be spread by infected urine and other secretions, and the portal of entry may be the mouth or conjunctiva, there is direct experimental evidence of its transmission during coition. Spontaneously infected boars have infected females in this way and produced "miliary brucellosis of the uterus" and abortion. Moreover, after experimental infection to newborn pigs, Brucella suis may remain viable in the seminal vesicles and the bladder for more than a year. The importance of the boar in the spread of infection has therefore been established.

During I929-32 there appeared in Denmark an epidemic of swine brucellosis involving 240 herds of swine, and the control of the disease entailed the examination of over 30,000 samples of blood by serological tests. Spread of the infection was mainly by boars during coition-one boar infected 25 herds. The epidemic was finally brought under control by destruction of infected animals or entire herds as soon as the presence of the disease was ascertained. This entailed a very thorough co-operation between the public veterinary administration and the diagnostic laboratory. In lightly infected herds, freedom from infection was successfully achieved by serological tests repeated every two months, with slaughter of the infected animals and disinfection of their pens. The owners of heavily infected herds were advised to kill the whole herd. It must be emphasised that Thomsen (I934) concludes that "swine brucellosis is a special disease of swine-in no direct relation to infectious abortion in cattle."

(2) SPIROChætosis

Human syphilis can be transmitted experimentally to monkeys, rabbits and guinea-pigs, but there is little 


\section{VENEREAL DISEASES OF ANIMALS}

evidence that the natural disease occurs in animais. Several authors, however (Jaureguy and Lancelotti, I924 ; Doléris, I925), believing that human syphilis originated in America, cite historical documents to support the contention that it was derived from the llama of South America, and record experiments on llamas, which, they say, easily contract human syphilis.

Rabbit spirochætosis, on the other hand, often referred to as rabbit syphilis, is a well-recognised naturally occurring disease, which may prove disconcerting to research workers.

Rabbit spirochatosis.-A spirochætal disease of rabbits has been recorded by observers in this country (Ross, I9I2; Bayon, I9I3; Adams et al., I928), in America (Warthin et al., I923; Noguchi, I928), and on the Continent (Bessemans, I928). It appears to be common among wild rabbits, has also been observed in rabbits bred for laboratory purposes, and is caused by a spirochæte morphologically similar to $T r$. pallidum. Many observers have recorded their experience because its presence may lead to fallacies in work on human syphilis in the rabbit, especially where superficial inoculation is practised.

The spirochæte responsible has been named Tr.cuniculi, and is apparently difficult to distinguish by morphology alone from $T r$. pallidum. Noguchi (I928) transmitted the disease to normal rabbits by inoculating with material containing spirochætes on the scarified prepuce or vulva. The period of incubation averaged about sixty days. Adams and others (1928) reproduced the disease by this method, and also by mating, but not with the same constancy as by scarification.

Noguchi showed the differences between $T r$. cuniculi and $T r$. pallidum by his failure to transmit rabbit syphilis to monkeys; whereas lesions appeared in a month in monkeys inoculated with material from a human chancre and also with a strain of $T r$. pallidum which had been passaged through rabbits. Further, whilst the intratesticular inoculation of emulsified lymph glands from rabbits infected with $T r$. pallidum produced orchitis in other rabbits, similar experiments with material from rabbits infected with $T r$. cuniculi failed to produce such lesions. Material containing $T r$. pallidum gives rise to chancre-like nodules when applied to the scari- 


\section{BRITISH JOURNAL OF VENEREAL DISEASES}

fied prepuce or vulva of rabbits, whilst the lesions produced by $T r$. cuniculi infection are small scaly patches, often slightly eroded and covered with a brownish crust.

The lesions of rabbit syphilis are confined to the superficial parts of the skin, and although the organism is present in large numbers and may be demonstrated by smears of secretions, it does not invade the tissues deeply. The lesions are papular or erosive, often covered with a brown crust, and situated in the genitals or perineal region. In recent infections the parts may be œdematous and the inguinal lymph glands enlarged. The lesions may be insignificant in size and the nostrils may be involved, being eroded with crusts, whilst lesions may also be found on the eyelids, which may be thickened and scaly and may bleed when gently rubbed. The general health of infected rabbits remains good, and no general immunity develops. (Warthin et al., I923.)

Diagnosis may be effected by examination for nakedeye lesions, especially about the genitals, nose, eyes and paws. Smears made after scarification may be examined by the dark background or after some staining method, such as Giemsa or Fontana, and histological sections of lesions may be stained by Levaditi's method. Warthin and his colleagues emphasise that the spontaneous disease may be differentiated from the experimental infection with $T r$. pallidum by the morphology of the parasite and the pathology of the lesions.

Noguchi subjected the sera of forty-four rabbits infected with Tr. cuniculi for periods varying from one to two weeks to several months to the Wassermann reaction. All the results were negative, whereas sixteen rabbits infected with $T r$. pallidum gave positive reactions.

Local treatment with unguentum hydrargyri (blue ointment) is regarded as effective by rabbit dealers, and proved so in the hands of Adams and his colleagues, who also report the curative effect of an intravenous injection of novarsenobillon (0.02 grm. per kilo.). Noguchi treated one rabbit infected with $T r$. cuniculi and one infected with $T r$. pallidum with salvarsan intravenously $(0.02 \mathrm{grm}$. per kilo.) and in both cases the lesions disappeared and no spirochætes could be found within a few days of administration. 


\section{VENEREAL DISEASES OF ANIMALS}

\section{(3) Trypanosomiasis}

Although most pathogenic trypanosomes are transmitted from host to host by means of flies, in one disease, namely dourine, the transmission is effected not through the agency of an intermediate host but by coitus.

Dourine is a trypanosomiasis of horses and donkeys caused by $T$. equiperdum. It is known to exist in parts of Europe, Africa, Asia and America.

The disease is usually chronic, and lasts for one to two -or in exceptional cases two to three-years. Affected animals nearly always die, with almost complete paraplegia and an extreme cachexia. Occasionally spontaneous recovery occurs.

The symptoms, which appear about a fortnight or more after coition, are inflammation and œdema of the genitalia. Later, raised plaques, which may persist for some days, appear on the skin. Generally there are nervous symptoms accompanied by fever, progressive anæmia, and death in about a year. Pregnant animals may abort.

By I9I4 the disease had been practically suppressed in many of the S.E. countries of Europe, but after the war I9I4-I8 it reappeared, owing no doubt to the movement of troops and the breakdown of preventive measures (Ciuca, 1933-34).

Diagnosis may be effected by :-

(a) Clinical observations; the essential signs being œdema of the genital region, cutaneous plaques, followed by nervous symptoms with paralysis and paraplegia.

(b) Microscopical examination. This is not very satisfactory; it is useless to examine blood films, for the trypanosomes are present in the blood-stream so rarely or in such small numbers as to escape observation. Examination of the exudate from areas of œdema and of fluid obtained from plaques is sometimes advocated, but even here the trypanosomes are difficult to demonstrate.

(c) Serological tests. The complement fixation test is recognised as being the most valuable.

(d) Inoculation of 100-400 c.c. of blood intraperitoneally to dogs may be of value in positive cases, as dogs are susceptible to artificial infection with $T$. equiperdum, but a negative finding does not exclude the possibility that dourine is present. 


\section{BRITISH JOURNAL OF VENEREAL DISEASES}

(e) Other tests, such as the formol-gelation of serum, may be used, but are not so reliable as the complement fixation test.

Various forms of treatment have been tried; neosalvarsan, naganol and novarsenobenzol have apparently given good results in some hands.

Watson (I9I5) has pointed out that horses may sometimes tolerate a dourine infection for a year or more and remain normal in general health and appearance, and since such animals are potential foci of infection the control of the disease is made more difficult. Watson has been largely responsible for the successful control of dourine in Canada, and advocates the use of the complement fixation test for the detection of infected animals. Various antigens may be used. Watson used trypanosomes from heavily infected rats' blood, and separated them from the blood cells by centrifugation; Zottner (I934) prepared a dried stable antigen by bleeding heavily infected rats into sodium citrate solution (O.I5 per cent.), separating and washing the trypanosomes by centrifugation and evaporating to dryness. An alcoholic suspension is prepared and kept, and for use the alcohol is evaporated and saline added. This antigen is considered an improvement on Watson's and compares favourably in complement fixation tests (Eyraud, I934). During I9I2-I9 the complement fixation test was applied to 40,000 horses in Canada, and infection was detected in many animals which clinically were not suspected of suffering from dourine. Animals giving a positive reaction were slaughtered, and consequently in Canada the disease has been eliminated. The test is apparently a group reaction, since $T$. brucei may be used as an antigen and animals suffering from other forms of trypanosomiasis may give positive reactions. As, however, horses are not bred in large numbers in tsetse fly areas where other forms of equine trypanosomiasis exist, the problem of group reactions does not often arise.

Eyraud (I934) in Morocco recommends the following programme of control :-

(a) Serological examination of blood of all stallions.

(b) Castration or slaughter of all reactors.

(c) Prevention by frequent injections of naganol.

Where castration or slaughter is not possible, treatment with novarsenobenzol is advocated. 


\section{VENEREAL DISEASES OF ANIMALS}

\section{(4) Trichomonas Infection}

This is a disease in cattle which is apparently transmitted during coition and caused by a protozoon, Trichomonas foetus.

Infection of Cattle with Trichomonas foetus.-There has been recognised for many years a disease of bovines characterised by certain difficulties in breeding, by abortion during the early months of pregnancy. and by pyometra and endometritis. Vaginitis may be an early sign. There is little doubt that the condition is spread by the bull during coition and the cause is generally considered to be a protozoon, Trichomonas fatus. This condition may occasion serious economic loss ; it has been noted on the Continent and in America, and quite recently has been shown to exist in this country (Stableforth, Scorgie and Gould, I937).

Trichomonas foetus is a flagellated protozoon which varies in size and shape. It is usually pear-shaped and I $2 \mu$ to $20 \mu$ long by $6 \mu$ to Io $\mu$ broad, is actively motile, and can be cultured artificially on certain media containing blood or serum. Trichomonas rumantium is apparently a distinct species, non-pathogenic and found in the rumen of bovines.

Although infection with Trichomonas foetus has only been observed in bovines, sheep and laboratory animals, such as guinea-pigs, may also be infected.

In a typical outbreak of infection in a herd, a number of cattle come into œstrus six weeks to three months after service, and there is a white mucous discharge from the vagina. Careful search may show that abortion has occurred, the discharged fœtus being a few inches only in length. The disease is often not recognised till many animals are infected and abortions and cases of chronic pyometra are common.

The condition is transmitted by the bull at service. In the bull the symptoms of infection which may or may not be present, are, in the early stages, a swelling of the prepuce and inflammation of the glans penis, while trichomonads may be found easily. On the other hand, a chronic condition may occur, in which no symptoms are apparent, and it is then difficult to tell whether the bull is infective or not.

After coition with an infected bull, a transient vaginitis 
may occur in the female. If conception has not taken place, this is followed by a chronic form of endometritis. If, however, the cow is pregnant, the fœtus dies and is either aborted one to four months later or retained in the uterus. When the fotus is retained, a pyometra develops, the uterus being filled with thick pus, and to the casual observer the animal appears to be normally pregnant. All these three conditions are often followed by sterility.

Diagnosis may be established by the examination of fresh material microscopically. Moist films examined under $I / 6$ lens are better than fixed stained ones, provided the material is not more than a few hours old and has been kept warm. Uterine discharges collected soon after abortion, the contents of the fourth stomach of a fœtus, or pus from pyometra should, when examined under such conditions, show actively motile trichomonads, if any are present.

Indirect serological methods, such as the complement fixation test, have sometimes been used in diagnosis. Two types, of antigen have been employed, namely, a suspension of trichomonads from the peritoneal exudate of an infected guinea-pig, and an extract of a culture of trichomonads. At the moment there is no evidence that this test has any advantage over the actual demonstration of the organism.

There is apparently no specific remedy, and treatment has followed the general lines of removing the uterine contents and douching with weak antiseptics. Apparently however, the disease is often cured spontaneously.

Preventive measures should be directed mainly towards the bull, and many observers doubt the advisability of breeding from a bull that has once been infective.

\section{(5) Tumour Formation}

The disease called by such names as " Venereal sarcoma of dogs," " contagious venereal tumours of dogs," is the one condition in dogs which can conceivably be classified as venereal. It has been known for many years, but is apparently rare now, for Wright (private communication) has seen only one case among approximately 50,000 dogs brought to the Royal Veterinary College during the past six years, and Stubbs and Furth (I934) report only five 


\section{VENEREAL DISEASES OF ANIMALS}

cases among approximately 3,000 dogs examined at the Veterinary Hospital of the University of Pennsylvania.

Contagious Venereal Tumours of Dogs.-One of the earliest British references is by Smith and Washbourn (I898). A dog with a growth situated on the penis, behind the corona, served twelve bitches between January and June, eleven of which became infected. The growths in the vagina appeared about a month after whelping, and increased in size until in some cases the whole vagina became filled. Constant bleeding from the vagina was a noticeable symptom. The tumours were removed surgically, but in some cases they reappeared. Three of the affected bitches were served by a second dog, which subsequently developed a growth on the penis, and infected one of two healthy bitches which he served later. As all the dogs belonged to one owner, this history can be readily accepted.

The growths may be single or multiple, and when advanced may be lobulated, and bleed readily on manipulation.

Bashford, Murray and Cramer (I905) investigated the condition, making histological observations and studying the history of infection. More especially, they compared the ease with which experimental transmission takes place with the failure of attempts to transmit carcinoma and sarcoma from dog to dog. Previous investigators had regarded the growths as belonging to the sarcomata or even carcinomata, but these workers concluded that the disease was a connective tissue reaction to a living virus which had not yet been demonstrated.

Recently, Jackson (I936) has completed a study of the Onderstepoort (South Africa) collection of neoplasms and has included venereal tumours and heart-base tumours of the dog. He stresses the point that these have consistently baffled attempts at satisfactory classification on a histological basis, but he regards them as true neoplasms. Histologically they are, in his opinion, difficult to differentiate from carcinomata. Their local invasive power is, however, limited, even though a definite encapsulation is not present. The tumour is not identical with any form of epithelial neoplasm with which one is familiar (Jackson, I936), but three heart-base tumours of dogs included in the study were identical histologically with the venereal tumours and were con- 
sidered to be neuroblastomas. Jackson emphasises the fact that these so-called venereal tumours may often occur on the superficial parts of the body, quite remote from the genitalia. The history of one of his cases, in which the tumour occurred in a bite-wound, suggests that the act of coitus is not the only method by which these tumours may be naturally transferred from one animal to another. Jackson regards the heart-base tumour as a possible spontaneously arising prototype of the venereal tumour.

Stubbs and Furth (1934) also refer to the difficulty of classification. They regard the venereal tumours as neoplasms, for although they transmitted them easily with viable tumour cells, they were unable to do so with Berkefeld filtrates of emulsions. The ability to transmit was also destroyed by 50 per cent. glycerin, by desiccation, by freezing and thawing, and by heating to $50^{\circ} \mathrm{C}$. for one and a half hours. These tumours are different from myxomata and certain other tumours of rabbits (Shope, I932), which are due to a filterable agent and originate from the body cells of the host. Stubbs and Furth therefore regard them as neoplasms, which often regress spontaneously and are the result of the multiplication of transplanted tumour cells.

\section{(6) Coital Exanthema}

Domesticated animals, particularly cattle and, less frequently, horses and sheep, may suffer from diseases of the external genitalia characterised by vesicular and pustular lesions. There seems little doubt that some at least of the conditions are contagious and spread during coition. There is, however, no generally accepted view as to whether there is more than one disease. Some authors divide the condition into :-

(i.) Vesicular exanthema, which affects cattle, horses and sheep, although it is not known whether one agent or more is responsible.

(ii.) Contagious granular vaginitis-a disease of cattle characterised in females by vaginal discharge and a nodular condition of the vaginal mucous membrane and in males by inflammation and granularity of the mucous membrane of the penis.

There seems to be no satisfactory evidence as to the 202 


\section{VENEREAL DISEASES OF ANIMALS}

actual cause or causes of these diseases, but it is assumed by certain workers that a virus or viruses are responsible. Complete recovery is the rule, and the treatment adopted is purely local.

In conclusion, one must emphasise the differences between the spread and control of animal and of human diseases. With animals it is customary, except in dogs and cats, to control sexual intercourse for breeding purposes ; only selected males and females are used, and the carriers or potential carriers of disease can be segregated, castrated or even slaughtered. Generally speaking, with animal diseases the economic point of view prevails, and this makes possible a control much more drastic than could be practised among human beings.

\section{REFERENCES}

Adams, D. K., Cappell, D. F., and McCluskie, J. A. W. (I928) : J. Path. \& Bact., 31, I57.

Bashford, E. F., Murray, J. A., and Cramer, W. (I 905) : $2 n d$ Rep. Imp. Cancer Research Fund, 33.

BAyon, H. (I9I3) : Brit. Med. Jour., 2, II59.

Bessemans, A. (I928) : C. R. Soc. Biol., 99, 33I.

CiucA, A. (1933-34) : Bull. Off. Internat. Epiz., \%, I68.

Doléris, M. (I925) : Bull. Acad. Méd., 93, 260.

Doyle, T. M. (1934) : J. Comp. Path. \& Ther., 47, I34.

EyRAUD (I934): Bull. Off. Internat. Epiz., 8, 4I4.

JACKson, C. (I936) : Onderstepoort Jour., 6, 387.

Jaureguy and Lancelotti (I924): Bull. Acad. Med., 92, I295.

Noguchi, H. (1928) : J. Exp. Med., 35, 39I.

Ross, E. H. (I9I2): Brit. Med. Jour., 2, I653.

SEDdon, H. R. (r9I9) : J. Comp. Path. \& Ther., 32, I.

SHope, R. E. (I932): J. Exp. Med., 56, 793.

5, 99 .

Smith, G. B., and Washbourn, J. W. (I898) : J. Path. \& Bact.,

Stableforth, A. W., Scorgie, N. J., and Gould, G. N. (I937) :

Vet. Rec., 49, 2 I I.

StubBs, E. L., and Furth, J. (I934): Amer. Jour. Path., 10, 275.

Thomsen, A. (1934) : Acta Path. Micro. Scand.-Supplement 21.

Warthin, A. S., Buffington, E., and Wanstrom, R. C. (I923) :

J. Inf. Dis., 32, 315 .

Watson, E. A. (I9I5): Parasitology, 8, 156.

Zottner, G. (I934): Bull. Soc. Path. Exot., 27, I59. 